\title{
Improved DRASTIC method for assessment of groundwater vulnerability to generic aqueous- phase contaminants
}

\author{
N. Z. Jovanovic ${ }^{1}$, S. Adams ${ }^{1}$, A. Thomas ${ }^{1}$, M. Fey ${ }^{2}$, \\ H. E. Beekman ${ }^{3}$, R. Campbell ${ }^{3}$, I. Saayman ${ }^{3} \&$ J. Conrad ${ }^{4}$ \\ ${ }^{1}$ Department of Earth Sciences, \\ University of the Western Cape, South Africa \\ ${ }^{2}$ Department of Soil Science, University of Stellenbosch, South Africa \\ ${ }^{3}$ CSIR, Stellenbosch, South Africa \\ ${ }^{4}$ GEOSS, Stellenbosch, South Africa
}

\begin{abstract}
Increased use and protection of groundwater resources are seen as possible solutions to mitigating water scarcity in arid and semi-arid regions. The DRASTIC index method is one of the most commonly used approaches to assess groundwater vulnerability to pollution. However, this method has been criticized in the past due to its subjectivity as well as the failure to account for some important hydrogeological characteristics (e.g. multi-layer vadose zone and preferential flow) and specific properties of contaminants (e.g. sorption and decay). These problems were addressed in this study with the objective of improving the DRASTIC method for assessment of groundwater vulnerability to generic aqueous-phase contaminants. Literature data and laboratory measurements were used in order to define categories and weighing factors for hydrogeological characteristics and specific contaminant properties. The new DRASTIC method developed in this study provides an improved categorization of the impact of the vadose zone, which accounts for the following factors: multi-layer vadose zone, based on site-specific conceptual models; hydraulic properties of the unsaturated zone (flow mechanism, drainage and travel time); and specific chemical properties (sorption and decay). The information was packaged in a user-friendly format for rating groundwater vulnerability. The method can be used for applications in site-specific environmental impact assessments for new developments, for regional groundwater vulnerability assessment as well as in integrated water resources management.
\end{abstract}

Keywords: decay, DRASTIC, groundwater vulnerability, hydraulic conductivity, preferential flow, recharge, sorption, travel time, vadose zone. 


\section{Introduction}

Increased use and protection of groundwater resources are seen as possible solutions to mitigating water scarcity in arid and semi-arid regions. Groundwater all over the world is becoming a natural resource of strategic importance due to its limited availability, quality deterioration, increasing demand and limited replenishment. In South Africa, water resources are generally scarce and unevenly distributed, and a large number of towns and rural settlements depend on groundwater for their drinking water supply and development. Previous research aimed at establishing a groundwater protection strategy (Sililo et al. [1]). One of the main outcomes of this research was that the vadose (unsaturated) zone, in particular the soil, should be seen as the "first line of defense" to transport of pollutants from overlying land-based sources to groundwater.

Groundwater vulnerability to contamination is defined as the tendency or likelihood for contaminants to reach a specified position in the groundwater system after introduction at some location above the uppermost aquifer (National Research Council [2]). The degree of groundwater contamination depends on the intrinsic hydrogeological characteristics and the physio-chemical properties of specific contaminants. Different types of pollutants are attenuated to a different degree depending on the characteristics of the site and speciation. Knowledge is therefore required on the properties of the porous medium through which the pollutant travels, the properties of the pollutant as well as the physical, chemical and biological processes (Sililo et al. [1]).

Several methods are available for assessing groundwater vulnerability. These were classified as index and overlay methods, process-based models and statistical methods (National Research Council [2]). Overlay and index methods are based on combining maps of various physiographic attributes (e.g. geology, soils, depth to water table) of the region and assigning a numerical index or score to each attribute. Process-based simulation models include analytical or numerical solutions to mathematical equations that represent processes governing contaminant transport. Statistical methods incorporate a probability of contamination as the dependent variable. Burkart et al. [3] presented examples of application of statistical, overlay and index, as well as process-based modeling methods for groundwater vulnerability assessment to a variety of data from the Midwest United States. Burkart and Feher [4] developed a strategy for regional groundwater vulnerability assessment that integrates elements of overlay, process-based and statistical methods.

Amongst the methods for assessment of groundwater vulnerability, the DRASTIC index (Aller et al. [5]) is the most commonly used in South Africa. This method makes use of the hydrogeological factors of an area in order to determine the relative groundwater vulnerability to contaminants. These hydrogeological factors, making up the acronym DRASTIC, are depth to water table, net recharge, material of the aquifer, soil properties, topography, properties of the vadose zone and hydraulic conductivity. Each factor is assigned a weight based on its relative importance to groundwater contamination potential, as well 
as a rating for different ranges of values. The DRASTIC index is then computed as the sum of the products of rating and weight for each factor. The DRASTIC index is generally built into Geographic Information Systems (GIS) - based maps to facilitate planning and management of groundwater protection, where each hydrogeological setting is a mappable unit with common hydrogeological factors (Thirumalaivasan et al. [6]). This practice, aimed at indicating areas at low, moderate or high risk from groundwater contamination, was applied in Israel (Secunda et al. [7]), Japan (Babiker et al. [8]), Jordan (Al-Adamat et al. [9]) and New Zealand (McLay et al. [10]).

The DRASTIC method has been criticized in the past due to its subjectivity as well as the lack of some important hydrogeological characteristics and specific properties of contaminants. For example, Dixon [11] indicated that groundwater contamination potential maps were more consistent with field data when soil structure was taken into consideration in a study conducted in Woodruff County in the Mississippi Delta region of Arkansas. Sandersen and Jorgensen [12] explained that, even when aquifers are deep-seated and appear to be well protected, preferential flow paths for downward transport of contaminated water from shallow aquifers may occur. Melloul and Collin [13] suggested that both vertical and lateral flow play an important role in groundwater contamination. Worrall et al. [14] found that interaction between site and chemical factors represents the most important process in the occurrence of pesticides in groundwater, based on multi-annual monitoring datasets from the United Kingdom and Mid-Western United States. Worrall and Kolpin [15] indicated that the best-fit model to predict the occurrence of herbicides in groundwater of the Mid-West United States combined organic carbon content, percentage sand content and depth to the water table with molecular descriptors representing molecular size, molecular branching and functional group composition of the herbicides.

In this study, the aim was to modify the original DRASTIC method (Aller et al. [5]) to account for some important hydrogeological characteristics (e.g. multi-layer vadose zone and preferential flow) and specific properties of contaminants (e.g. sorption and decay) in order to improve, in particular, the reliability of the rating "I" (impact of the vadose zone). An additional aim was to provide a more detailed (less subjective) description of the ratings in order to adapt the DRASTIC method for assessment of groundwater vulnerability to generic aqueous-phase contaminants under South African environmental conditions.

\section{Improved DRASTIC method}

The rating of the vadose zone (high, medium and low) is based on a combination of factors that contribute to the likelihood of contaminants reaching the saturated zone following the path of aquifer recharge. The ability of the vadose zone to attenuate and/or prevent any contaminant from reaching groundwater depends on the following factors: thickness of the unsaturated zone, hydraulic properties and flow mechanism, recharge, travel time, sorption and decay. The approach used in 
order to improve DRASTIC, involved the description and quantification of these factors, as well as the provision of guidelines to assist in quantifying their relative importance. The factors are discussed individually below.

The thickness of the unsaturated zone depends on the nature of both aquifer (confined, unconfined, leaky and semi-confined) and regolith material (unconsolidated, consolidated, weathered, consolidated fractured or a combination). Table 1 summarizes the impact of the thickness of the unsaturated zone and the type of media on groundwater vulnerability. The ranges of values reported in Table 1 were estimated based on experience.

Table 1: Unsaturated zone thicknesses, type of media and resulting impact on groundwater vulnerability.

\begin{tabular}{|c|c|c|c|c|}
\hline \multicolumn{2}{|c|}{ Unsaturated zone medium } & \multicolumn{3}{|c|}{ Thickness (m) } \\
\hline \multirow{4}{*}{ Unconsolidated material } & Gravel & $>50$ & $30-50$ & $0-30$ \\
\cline { 2 - 5 } & Clean sand & $>50$ & $30-50$ & $0-30$ \\
\cline { 2 - 5 } & Silty sand & $>30$ & $15-30$ & $0-15$ \\
\cline { 2 - 5 } & Silt & $>15$ & $5-15$ & $0-5$ \\
\cline { 2 - 5 } & Clay & $>5$ & $2.5-5$ & $0-2.5$ \\
\hline Consolidated fractured medium & $>30$ & $5-30$ & $0-5$ \\
\hline Leaky aquifers & $>30$ & $5-30$ & $0-5$ \\
\hline & \multicolumn{3}{|c|}{ Vulnerability impact } \\
\cline { 2 - 5 } & Low & Medium & High \\
\cline { 2 - 5 }
\end{tabular}

The dominant mechanism of aqueous-phase contaminants transport in the unsaturated zone is by advection along wetting front edges (with water content close to saturation) during the infiltration process. Due to this transport mechanism, the inaccessibility, high cost of measurement and spatial variability, saturated hydraulic conductivity is often used as a substitute for unsaturated hydraulic conductivity. Typical values of saturated hydraulic conductivity for most porous media are easily accessible (Freeze and Cherry [16]). Unsaturated hydraulic conductivity can be estimated if additional hydraulic properties of the medium are known, e.g. the water retention curve (Van Genuchten et al. [17]). The vertical hydraulic conductance is then calculated as a function of hydraulic conductivity (Eimers et al. [18]). The ranges of values for the impact of vertical hydraulic conductance on groundwater vulnerability are defined in Table 2.

Preferential flow is a complicating factor in estimating travel times of contaminants in dual porosity environments. Dual porosity consists of two interacting pore regions with different hydraulic properties, the one associated with the macro-pore or fracture network, and the other with micro-pores inside soil aggregates or rock matrix blocks. It is generally assumed that flow occurring through preferential paths is fast (Table 2), resulting in lower contaminant attenuation through, for example, sorption and decay.

The definition of recharge used in this study is the amount of rainfall that reaches the saturated zone, either by direct contact in the riparian zone or by downward percolation through the unsaturated zone (Rushton and Ward [19]). 
Aquifer recharge depends on factors such as groundwater depth, climate, geology (lithology and structures), geomorphology, vegetation, soil conditions and antecedent soil moisture. A variety of methods can be applied for the estimation of recharge in semi-arid conditions, e.g. CMB (Chloride Mass Balance), CRD (Cumulative Rainfall Departures), EARTH model (Xu and Beekman [20]), as well as the "Qualified Guess" method based on information on soil, vegetation, geology as well as South African maps of groundwater recharge, recharge of soil water into the vadose zone and harvest potential. The rating of recharge rate is defined in Table 3 for various unsaturated zone thicknesses.

Table 2: Unsaturated zone flow mechanism, hydraulic properties and resulting impact on groundwater vulnerability.

\begin{tabular}{|c|c|c|c|}
\hline Flow mechanism & \multicolumn{3}{|c|}{ Vertical hydraulic conductance $\left(\mathrm{m}^{2} \mathrm{~d}^{-1}\right)$} \\
\hline Matrix & $<45$ & $45-9000$ & $>9000$ \\
\hline Preferential & & & $>1$ \\
\hline \multirow{3}{*}{} & \multicolumn{3}{|c|}{ Vulnerability impact } \\
\cline { 2 - 4 } & Low & Medium & High \\
\cline { 2 - 3 }
\end{tabular}

Table 3: Unsaturated zone thickness, recharge and resulting impact on groundwater vulnerability.

\begin{tabular}{|c|c|c|c|}
\hline Thickness $(\mathrm{m})$ & \multicolumn{3}{|c|}{ Recharge $\left(\mathrm{mm} \mathrm{a}^{-1}\right)$} \\
\hline $0-5$ & $0-1$ & $1-5$ & $>5$ \\
\hline $5-30$ & $0-5$ & $5-10$ & $>10$ \\
\hline$>30$ & $0-10$ & $10-100$ & $>100$ \\
\hline \multirow{4}{*}{} & \multicolumn{3}{|c|}{ Vulnerability impact } \\
\cline { 2 - 4 } & Low & Medium & High \\
\cline { 2 - 4 }
\end{tabular}

Table 4: Unsaturated zone media type, travel time to water table and resulting impact on groundwater vulnerability for a $5 \mathrm{~m}$ thick unsaturated zone.

\begin{tabular}{|c|c|c|c|c|}
\hline \multicolumn{2}{|c|}{ Unsaturated zone medium } & \multicolumn{3}{|c|}{ Travel time } \\
\hline \multirow{5}{*}{ Unconsolidated material } & Gravel & & & $<1 \mathrm{~h}$ \\
\hline & Clean sand & & $1 \mathrm{mo}$ & $1 \mathrm{~d}$ \\
\hline & Silty sand & $>1 \mathrm{a}$ & $<1 \mathrm{a}$ & $<1 \mathrm{mo}$ \\
\hline & Silt & $>0.5 \mathrm{a}$ & $<0.5 \mathrm{a}$ & $<1 \mathrm{mo}$ \\
\hline & Clay & $>>1 \mathrm{a}$ & & \\
\hline \multirow{3}{*}{\multicolumn{2}{|c|}{ Consolidated fractured medium }} & $>1 \mathrm{a}$ & $1 \mathrm{mo}$ & $1 \mathrm{~h}-1 \mathrm{~d}$ \\
\hline & & \multicolumn{3}{|c|}{ Vulnerability impact } \\
\hline & & Low & Medium & High \\
\hline
\end{tabular}

Travel time is the time it takes a contaminant to move from the soil surface to the groundwater. This can be calculated as the ratio of the travel distance divided by flow velocity, where flow velocity is the volumetric flux divided by the 
volumetric water content. Alternatively, Foster and Hirata [21] suggested simple equations to calculate travel time as a function of unsaturated zone thickness, effective porosity and saturated hydraulic conductivity (gross surcharging conditions), or specific retention and annual infiltration (natural infiltration conditions). The travel time rating for various vadose zone media is defined in Table 4 . The database can be further expanded to include different thicknesses of the vadose zone.

Extensive laboratory experiments were undertaken in order to correlate sorption of different groups of contaminants to soil properties. The experiments made use of an extensive database of soil samples collected in South Africa over several decades. Sorption of representative cationic metals $(\mathrm{Cu}$ and $\mathrm{Zn})$ and anions $\left(\mathrm{SO}_{4}\right.$ and $\left.\mathrm{PO}_{4}\right)$ was measured on a large number of soil horizons. The main outcome of the laboratory experiments was that the diagnostic horizons, as defined by the Soil Classification Working Group [22], are not good predictors of sorption. However, six soil properties were found to somewhat correlate to sorption, namely clay content, organic matter content, $\mathrm{pH}$, exchangeable basic cations, extractable Fe and Al. It was observed that sorption is variable within certain ranges or maximum values of these properties, and unlikely beyond these limiting values. The impact of sorption on groundwater vulnerability was therefore defined as in Table 5 .

Table 5: Contaminant species, sorption in different soil types and resulting impact on groundwater vulnerability.

\begin{tabular}{|c|c|c|c|}
\hline Contaminants & \multicolumn{3}{|c|}{ Soil properties } \\
\hline $\begin{array}{c}\text { Cationic } \\
\text { (inorganic and } \\
\text { polar organic) }\end{array}$ & $\begin{array}{c}\text { Thick, clayey profiles, } \\
\text { margalitic soils; strongly } \\
\text { calcareous clays; } \\
\text { eutrophic peats }\end{array}$ & $\begin{array}{c}\text { All other } \\
\text { soils }\end{array}$ & $\begin{array}{c}\text { Dystrophic } \\
\text { sands low in } \\
\text { humus }\end{array}$ \\
\hline $\begin{array}{c}\text { Anionic (inorganic } \\
\text { and polar organic) }\end{array}$ & $\begin{array}{c}\text { Deep, dystrophic, } \\
\text { ferrallic clays }\end{array}$ & $\begin{array}{c}\text { All other } \\
\text { soils }\end{array}$ & $\begin{array}{c}\text { Eutrophic } \\
\text { sands }\end{array}$ \\
\hline $\begin{array}{c}\text { Organic (non- } \\
\text { polar) }\end{array}$ & $\begin{array}{c}\text { Deep humic clays and } \\
\text { peats }\end{array}$ & $\begin{array}{c}\text { All other } \\
\text { soils }\end{array}$ & $\begin{array}{c}\text { Pure sands low } \\
\text { in humus }\end{array}$ \\
\cline { 2 - 4 } & Low Vulnerability impact \\
\cline { 2 - 4 } & Variable & High \\
\hline
\end{tabular}

Table 6: Unsaturated zone sorption capacity, contaminant persistence and resulting impact on groundwater vulnerability.

\begin{tabular}{|c|c|c|c|}
\hline Sorption capacity & \multicolumn{3}{|c|}{ Half-life } \\
\hline Low & $<1 \mathrm{~h}$ & $1-24 \mathrm{~h}$ & $>24 \mathrm{~h}$ \\
\hline Variable & $<1 \mathrm{~d}$ & $1-15 \mathrm{~d}$ & $>30 \mathrm{~d}$ \\
\hline High & $<15 \mathrm{~d}$ & $15-50 \mathrm{~d}$ & $>50 \mathrm{~d}$ \\
\hline \multirow{4}{*}{} & \multicolumn{3}{|c|}{ Vulnerability impact } \\
\cline { 2 - 4 } & Low & Medium & High \\
\cline { 2 - 4 }
\end{tabular}


Decay, expressed in terms of half-life, is related to organic contaminants subjected to physical (e.g. photolysis), chemical (e.g. hydrolysis) and biological (e.g. microbial) degradation. Half-lives of specific contaminants may vary by orders of magnitude depending on environmental factors (e.g. microbiological activity, $\mathrm{pH}$, moisture, temperature etc.). A database of half-lives and other properties of contaminants was compiled by Usher et al. [23]. The impact of decay on groundwater vulnerability was defined in Table 6.

\section{Software application}

The rating of the factors relevant to the attenuation of contaminants in the vadose zone was incorporated into a user-friendly Excel-based calculator of the improved DRASTIC index. An example printout of the main menu of the improved DRASTIC calculator is shown in Figure 1. The purpose of the main menu is to summarize scores for each factor based on rating and weighing. The ratings for each factor are determined in sub-menus that include guidelines and theoretical description. The improved DRASTIC calculator also allows for a multi-layer vadose zone.

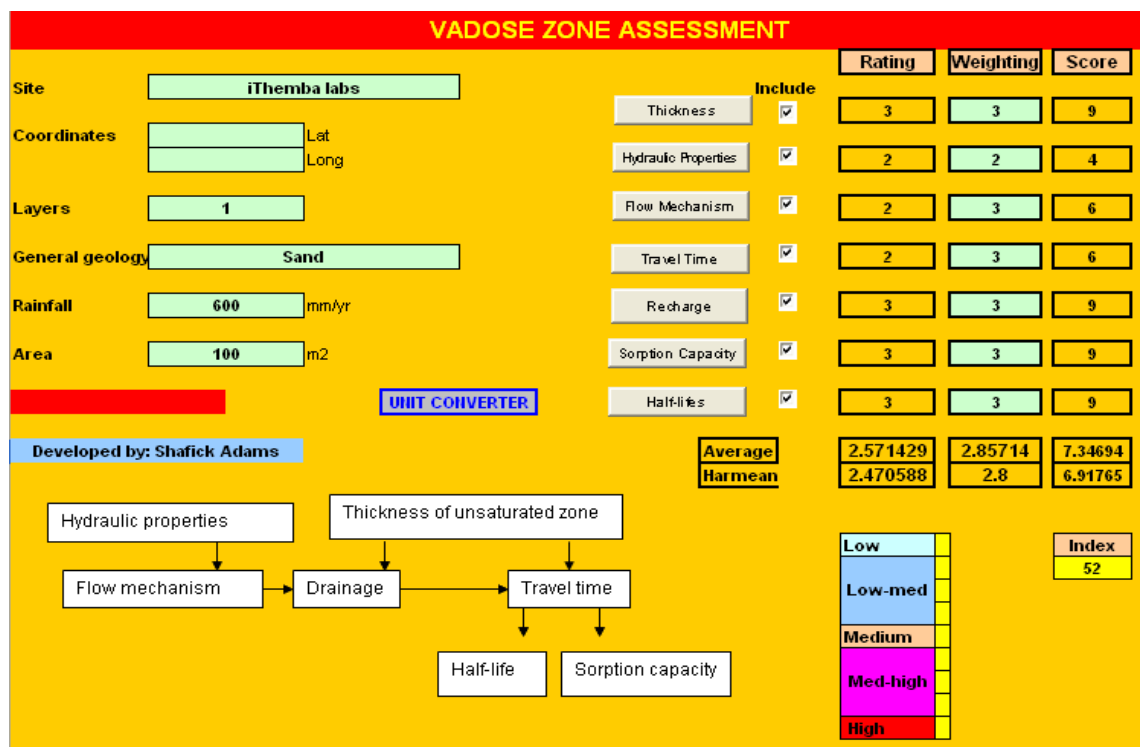

Figure 1: Example printout of the main menu of the Excel-based improved DRASTIC index calculator.

The vulnerability of an aquifer to contamination originating at the soil surface can be assessed using data that are readily available, that can be calculated or that can be estimated using the information provided in the database of the improved DRASTIC calculator, based on a step-by-step procedure and conceptual models for specific sites. The first step in the procedure is to define 
the unsaturated zone thicknesses using water level depths and national groundwater databases, as well as the nature of the unsaturated zone using borehole logs. The rating for the unsaturated zone thickness is then selected (Table 1). The second step involves the calculation of the vertical hydraulic conductance using available data (Freeze and Cherry [16]; Van Genuchten et al. [17]; Eimers et al. [18]), as well as the estimation of dominant flow mechanisms from available borehole logs and geological information. The rating for hydraulic properties and flow mechanism is then selected (Table 2). The next step is the estimation of recharge using available information and any of the methods included in the software ("Qualified Guess", CMB, CRD, EARTH). The rating for recharge is selected from Table 3. Travel time is calculated using available data and any of the methods included in the software (flow velocity; Foster and Hirata [21]). The rating for travel time is selected using Table 4. Sorption is defined from available information on soils and types of contaminants, whilst decay is determined based on the contaminant species and the database of their properties (Usher et al. [23]). The rating for sorption is selected from Table 5, whilst the rating for half-lives is selected from Table 6. The rating scores for each factor are finally combined in the main menu to yield the rating of the impact of vadose zone on groundwater vulnerability.

\section{Conclusions}

An improved DRASTIC index was developed to account for hydrogeological factors like multi-layer vadose zone and preferential flow, as well as specific properties of contaminants like sorption and decay. In addition, a database of values and descriptors related to the rating "I" (impact of the vadose zone) was included in a user-friendly, Excel-based, improved DRASTIC index calculator. The algorithms presented in this study can be easily included into a GIS system for assessment of groundwater vulnerability at different scales.

The method can be used for applications in site-specific environmental impact assessments for new developments, for regional groundwater vulnerability assessment as well as in integrated water resource management. This has, however, implications with uncertainties of groundwater vulnerability assessment as well as data availability and scarcity. The level of uncertainty increases with the coarsening of input data. Similarly, the level of uncertainty and accuracy is associated with the coarsest dataset. National data sets can be used in the absence of field data. However, the recommended approach is to assess vulnerability at a site-specific scale. If finer resolution data sets are available for the area being studied, then improved levels of data certainty will be achieved.

\section{Acknowledgement}

The authors acknowledge the funding of the Water Research Commission (Pretoria, South Africa) through the research project on "Improved methods for 
aquifer vulnerability assessment and protocols for producing vulnerability maps, taking into account information on soils".

\section{References}

[1] Sililo, O.T.N, Saayman, I.C. \& Fey, M.V., Groundwater Vulnerability to Pollution in Urban Catchments, Water Research Commission Report No. 1008/1/01: Pretoria, South Africa, 2001.

[2] National Research Council, Groundwater Vulnerability Assessment: Predicting Relative Contamination Potential under Conditions of Uncertainty, Committee for Assessing Groundwater Vulnerability, National Academy Press: Washington, D.C., 1993.

[3] Burkart, M.R., Kolpin, D.W. \& James, D.E., Assessing groundwater vulnerability to agrichemical contamination in the Midwest US. Water Science and Technology, 39(3), pp. 103-112, 1999.

[4] Burkart, M.R. \& Feher, J., Regional estimation of ground water vulnerability to nonpoint sources of agricultural chemicals. Water Science and Technology, 33(4-5), pp. 241-247, 1996.

[5] Aller, L., Bennet, T., Lehr, J.H. \& Petty, R.J., DRASTIC - A Standardized System for Evaluating Groundwater Pollution Potential Using Hydrogeological Settings, EPA Report 600/2-87/035: US Environmental Protection Agency, 1987.

[6] Thirumalaivasan, D., Karmegam, M. \& Venugopal, K., AHP-DRASTIC: software for specific aquifer vulnerability assessment using DRASTIC model and GIS. Environmental Modelling \& Software, 18(7), pp. 645-656, 2003.

[7] Secunda, S., Collin, M.L. \& Melloul, A.J., Groundwater vulnerability assessment using a composite model combining DRASTIC with extensive agricultural land use in Israel's Sharon region. Journal of Environmental Management, 54(1), pp. 39-57, 1998.

[8] Babiker, I.S., Mohamed, A.A., Hiyama, T. \& Kato, K., A GIS-based DRASTIC model for assessing aquifer vulnerability in Kakamigahara Heights, Gifu Prefecture, central Japan. Science of the Total Environment, 345(1-3), pp. 127-140, 2005.

[9] Al-Adamat, R.A.N., Foster, I.D.L. \& Baban, S.M.J., Groundwater vulnerability and risk mapping for the Basaltic aquifer of the Azraq basin of Jordan using GIS, Remote sensing and DRASTIC. Applied Geography, 23(4), pp. 303-324, 2003.

[10] McLay, C.D.A., Dragten, R., Sparling, R. \& Selvarajah, N., Predicting groundwater nitrate concentrations in a region of mixed agricultural land use: a comparison of three approaches. Environmental Pollution, 115(2), pp. 191-204, 2001.

[11] Dixon, B., Groundwater vulnerability mapping: A GIS and fuzzy rule based integrated tool. Applied Geography, 25(4), pp. 327-347, 2005.

[12] Sandersen, P.B.E. \& Jorgensen, F., Buried Quaternary valleys in western Denmark-occurrence and inferred implications for groundwater 
resources and vulnerability. Journal of Applied Geophysics, 53(4), pp. 229-248, 2003.

[13] Melloul, A.J. \& Collin, M., A proposed index for aquifer water-quality assessment: the case of Israel's Sharon region. Journal of Environmental Management, 54(2), pp. 131-142, 1998.

[14] Worrall, F., Besien, T. \& Kolpin, D.W., Groundwater vulnerability: interactions of chemical and site properties. The Science of The Total Environment, 299(1-3), pp. 131-143, 2002.

[15] Worrall, F. \& Kolpin, D.W., Aquifer vulnerability to pesticide pollutioncombining soil, land-use and aquifer properties with molecular descriptors.

Journal of Hydrology, 293(1-4), pp. 191-204, 2004.

[16] Freeze, R. \& Cherry, J.A., Groundwater, Prentice-Hall Inc.: New Jersey, 1979.

[17] Van Genuchten, M. Th., Leij, F.J. \& Yates, S.R., The RETC Code for Quantifying the Hydraulic Functions of Unsaturated Soils, EPA Report 600/2-91/065: US Environmental Protection Agency, 1991.

[18] Eimers, J.L., Weaver, J.C., Terziotti, S. \& Midgette, R.W., Methods of Rating the Unsaturated Zone and Watershed Characteristics of Public Water Supplies in North Carolina, Water Resources Investigations Report 99-4283: US Geological Survey, 2000.

[19] Rushton, K.R. \& Ward, C., The estimation of groundwater recharge. Journal of Hydrology, 41, pp. 345-361, 1979.

[20] Xu, Y. \& Beekman, H.E., (eds). Groundwater Recharge Estimation in Southern Africa. UNESCO IHP Series No. 64: UNESCO, Paris, 2003.

[21] Foster, S.S.D. \& Hirata, R., Groundwater Contaminant Risk Assessment: A Methodology Using Available Data, Pan American Centre for Sanitary Engineering and Environmental Sciences (CEPIS): Lima, Peru, 1995.

[22] Soil Classification Working Group, Soil Classification. A Taxonomic System for South Africa, Dept. of Agricultural Development: Pretoria, South Africa, 1991.

[23] Usher, B., Pretorius, J.A., Dennis, I., Jovanovic, N., Clarke, S., Cave, L., Titus, R. \& Xu, Y., Identification and Prioritization of Groundwater Contaminants and Sources in South Africa's Urban Catchments, Water Research Commission Report No. 1326/1/04: Pretoria, South Africa, 2004. 